\title{
Media Sosial Sebagai Sarana Membentuk Identitas Diri Mahasiswa Universitas Airlangga Surabaya
}

\author{
Dinda Marta Almas Zakirah ${ }^{1}$ \\ UIN Sunan Ampel Surabaya \\ dindamarta17@gmail.com
}

\begin{abstract}
Currently, technology does not only provide ease for the users but also creates some social media that makes the users be able communicating from distances. Social media can also be used to share any photos and videos such as the one that is being the favorite of its users namely instagram. However, instagram is no longer functions for photo and video sharing but to form self-image. Many youth try to build up their self-images on instagram and many of them are students of Airlangga University. Therefore, this research is conducted to know how students of Airlangga University form their self-images on instagram. This research uses qualitative approach. The data collection technique in this research is in-depth interview and field observation. The theories used in this research are hiperrealitas Jean Baudrillard andNet Generation Theoryfrom Don Tapscott. Then, the sampling uses purposive method. The subjects of this research are 8 students consisting female and male students of Airlangga Universitywho are included in two instagram accounts namely @ satuunair and@unairhitspeople. The result of this research reveals that students of UNAIR form their self-images on instagram. They do it by editing the photo they will share on instagram, also the selection of location and angle for a photo. Besides, forming self-identity on social media does not fully give negative effect.By the internet and smart phones, the intensity to use smart phones gets bigger than before the internet existed. Hence, it proofs that they get positive beneficial impact.
\end{abstract}

Keywords: University student, social media, instagram, self-image, net generation.

\begin{abstract}
Abstrak
Teknologi kini tidak hanya menyediakan kemudahan bagi pengguna, teknologi kini melahirkan beberapa media sosial yang dapat membuat penggunanya mampu untuk berkomunikasi jarak jauh. Bukan hanya itu, media sosial juga dapat membagikan foto dan video apapun seperti media sosial yang saat ini sedang banyak di gandrungi oleh pengguna media sosial, yaitu instagram. Namun kini instagram bukan lagi untuk media membagikan foto atau video lagi, melainkan wadah untuk membentuk citra diri. Banyak di kalangan anak muda yang memmbentuk citra diri di instagram, yang salah satunya mahasiswa dan mahasiswi Universitas Airlangga. Oleh karena itu dilakukan penelitian tentang bagaimana mahasiswa dan mahasiswi Universitas Airlangga membentuk citra diri di media sosial instagram. Penelitian ini menggunakan pendekatan kualitatif. Teknik pengumpulan data dalam penelitian ini yaitu wawancara secara mendalam dan observasi lapangan. Teori yang digubahkan dalam penelitian ini adalah teori hiperrealitas Jean Baudrilland dan Net Generation Theory dari Don Tapscott. Kemudian Teknik pengambilan data menggunakan metode purposive. Subjek dalam
\end{abstract}


penelitian ini adalah 8 mahasiswa dan mahasiswi Universitas Airlangga yang termasuk dalam akun@satuunair dan@unairpeople. Hasil dari penelitian ini adalah bahwa mahasiswa UNAIR memang membentuk citra diri di media sosial Instagram. Cara mahasiswa untuk membentuk citra diri mereka dengan cara memberikan editan yang sesuai dengan foto yang akan dibagikan di Instagram, kemudian pemilihan lokasi dan angel dalam sebuah foto. Selain itu, tidak sepenuhnya membentuk citra diri di media sosial mendapatkan dampak yang negatif. Kemudian dengan adanya teknologi internet dan dibekali dengan smartphone, intensitas untuk menggunakan smartphone lebih besar dibandingkan sebelum maraknya teknologi internet. Dari hasil penelitian ini membuktikan bahwa mereka mendapatkan dampak positif yang menguntungkan.

\section{Kata Kunci: Mabasiswa, media sosial, instagram, citra diri, net generation Pendahuluan}

Dewasa ini teknologi semakin canggih, mulai dari orang dewasa hingga anak-anak sudah dapat menggunakan internet melalui handphone, laptop dan alat komunikasi lainnya, dengan kemajuan teknologi yang semakin canggih ini masyarakat dapat dengan mudah untuk meng-akses apa yang dibutuhkannya dengan waktu yang relatif cepat, serta mudah cara penggunaannya.

Kini pertumbuhan internet semakin cepat di kalangan masyarakat post-modern. Di satu sisi mungkin benar telah melahirkan berbagai macam ruang publik yang mungkin terbuka atau umum dan bahkan tanpa batas untuk menjadi saluran bagi anak-anak muda untuk menyampaikan pendapat tentang sosial-politiknya. Namun di sisi yang lain, dengan kehadiran ruang publik yang ada di cyberspaceternyata malah merangsang tumbuhnya perilaku dan gaya hidup yang berbeda yaitu gaya hidup remaja urban yang lebih banyak di kendalikan oleh hasrat dan keinginan untuk terus membeli produk-produk atau barangbarang industri budaya terbaru daripada idealisme untuk memperjuangkan kepentingan dan perkembangan demokrasi. ${ }^{1}$

Perkembangan teknologi informasi dan komunikasi kini telah merubah cara interaksi antar indovidu. Kini internet menjadi sebuah ruang digital yang menciptakan sebuah ruang kultural. Tidak dapat dipungkiri bahwa dengan keberadaan internet memberikan banyak kemudahan kepada penggunanya. Beragam akses terhadap informasi dan hiburan dari berbagai penjuru dunia dapat dicari melalui internet. Internet juga menembus batas dimensi kehidupan pengguna, waktu dan ruang, yang dapat di akses oleh

1 Rahma Sugihartati, Perkembangan ,asyarakat Informasi dan Teori Sosial Kontemporer, (Jakarta: Kencana Prenada, 2014), hal 28.

Jurnal Kopis: Kajian Penelitian dan Pemikiran Komunikasi Penyiaran Islam

Volume 2 issue 2 bulan Februari tahun 2020 
siapapun, kapanpun dan dimanapun. ${ }^{2}$ Kemudian perkembangan teknologi informasi dan teknologi komunikasi terus mengalami kemajuan yang pesat. Dengan hadirnya internet di era 1990-an menjadi faktor pendukung perkembangan era teknologi komunikasi dan informasi hingga tahun 2004.

Cara manusia untuk saling berkomuniksi juga berkembang terus menerus mengikuti perkembangan teknologi. Teknologi komunikasi berkembang sangat pesat, hingga dapat menghadirkan beragm aplikasi pesan antar (instant messaging)dan juga beragam model Web 2.0 sebagai sarana komunikasi antar pengguna internet. Era ini disebut juga sebagi era media baru atau new media ${ }^{3}$.

Dengan keberadaan internet, secara tidak langsung menghasilkan sebuah generasi yang baru, yaitu generasi net. Generasi ini dipandang menjadi sebuah generasi masa depan yang diasuh dan di besarkan dalam lingkungan budaya baru media digital yang interaktif, yang berwatak meyendiri, kemudian berkomunikasi secara personal, melek komputer atau melek teknologi, dan dibesarkan dengn videogames ${ }^{4}$.

Kehadiran media sosial di kalangan anak muda kini membuat ruang privat seorang individu menjadi ruang publik. Terjadi pergeseran budaya di kalangan anak muda. Para anak muda kini tidak segan-segan membagikan segala bentuk kegiatan yang bersifat pribadi ataupun tidak pribadi untuk di sampaikan kepada teman-temannya melalui akun media sosial dalam membentuk identitas diri mereka. ${ }^{5}$

Salah satu media sosial seperti Instagram muncul pada 6 Oktober 2010 yang semakin berjalannya waktu instagram semakin bertambah penggunanya. Instagram ini dirancang oleh Kevin Systrom dan Mike Krieger. Instagram adalah salah satu aplikasi yang gunanya untuk berbagi foto yang memungkinkan pengguna menggambil foto, menerapkan filter digital, dan membagikannya ke berbagai layanan jejaring sosial, termasuk milik instagram sendiri. Instagram juga menjadi wadah untuk membentuk citra diri, dimana semakin banyak angka followers atau pengikut dan like (menyukai) di beberapa foto si pemilik akun akan semakin terlihat bahwa si pengguna memiliki citra diri yang tinggi, juga dapat menjadi figur bagi remaja-remaja masa kini'.

2 Primada Qurrota Ayun, "Fenomena Remaja Menggunakan Media Sosial Dalam Membentuk Identitas" (Skripsi-Universitas Ahmad Dahlan Yogyakarta, 2015) hal 1.

3 Putri Dwi Arlin, "Analisis Perilaku Pencarian Informasi Mengenai Breastfeeding Pada Ibu Net Generation" (Tesis-Universitas Airlangga Surabaya, 2015), hal 11.

4 Primada Qurrota Ayun, "Fenomena Remaja Menggunakan Media Sosial Dalam Membentuk Identitas" (Skripsi-Universitas Ahmad Dahlan Yogyakarta, 2015) hal 1.

5 Ibid., hal 2.

${ }^{6}$ Febriana Merri, "Hiperrealitas Angka Dalam Instagram-2016), hal 11. Jurnal Kopis: Kajian Penelitian dan Pemikiran Komunikasi Penyiaran Islam 
Pengertian tentang citra diri sendiri yakni gambaran umum tentang diri sendiri atau pandangan yang kita buat untuk diri kita sendiri, mungkin citra diri ini tidak sama dengan kenyataan yang terjadi, tetapi kita meyakininya. Citra diri ini membentuk suatu kepribadian kita bagaimana kita berlaku, berpenampilan, mengambil keputusan, termasuk menghargai kondisi tubuh.

Citra diri akan terbentuk jika seseorang menunjukan gaya hidup atau penampilan yang menarik hingga membuat orang lain terkesan atau menyukai gaya hidup dan penampilannya, melalui media sosial instagram, seseorang dapat membangun citra dirinya dengan memposting foto atau videonya di suatu tempat yang terkenal atau di tempat kelas menengah atas, padahal realita yang sebenarnya tak sedikit seseorang yang berada di lapisan bawah yang sering sekali bergaya atau berfoto di suatu tempat yang kelas menengah keatas, kemudian bergaya yang seolah membuat dirinya lebih menarik, kemudian mengupload foto tersebut ke instagram untuk mendapatkan like dan follower yang banyak, kemudian timbullah hiperrealitas seseorang yang akan melahirkan citra diri orang tersebut ${ }^{7}$.

Citra diri melekat pada diri masyarakat. Meski hanya untuk bepergian di dekat atau sekitar rumah, seseorang harus touch up atau dandan terlebih dahulu agar terlihat rapi dan menarik. Orang mana yang ingin terlihat tidak menarik atau penampilan yang acak-cakan dan tidak rapi di depan publik. Di Universitas Airlangga Surabaya yang sudah sangat terkenal dengan mahasiswa dan mahasiswi yang di mata publik terlihat begitu menarik dan berprestasi, hal ini dibuktikan dengan adanya akun instagram yang memiliki user name @unairhitspeople, @satuunair. Studi ini akan mengkaji mengenai bagaimana mahasiswa Universitas Airlangga dalam membentuk citra diri di media sosial instagram dan mengapa mahasiswa Universitas Airlangga membentuk citra diri di media sosial instagram

\section{Metode}

Penelitian ini menggunakan pendekatan kualitatif. Pendekatan kualitatif dapat mendiskripsikan suatu kondisi yang berawal dari fenomena yang ada dalam kehidupan sehari-hari, yaitu meliputi perilaku yang mengarah pada perilau membentuk citra diri mahasiswa dan mahasiswi dalam instagram. pendekatan kualitatif ini bertujuan untuk memahami makna citra diri bagi mahasiswa dan mahasiswi serta bagaimana mereka membentuk citra diri di media sosial instagram. Pemilihan tipe penelitian seperti ini sesuai

7 Herlinda Fitria, "Hiperrealitas Dalam Sosial Media (studi kasus: Makan Cantik Di Senopati Pada Masyarakat Perkotaan)" (Skripsi-Universitas Indonesia, 2013), hal 88. 
dengan permasalahan yang di angkat peneliti pada suatu studi ini.Pendekatan kualitatif ini digunakan untuk menjelaskan interaksi sosial, dengan dilakukannya wawancara mendalam hingga didapatkannya data yang dibutuhkan oleh peneliti.

Peneliti menggunakan metode purposive dalam memilih informan dengan kriteria tertentu yakni, mahasiswa Universitas Airlangga, mahasiswa yang memiliki akun instagram, mahasiswa dengan followers terbanyak, mahasiswa yang masuk dalam akun instagram @satuunair dan@unairhitspeople. Tujuan dari kriteria informan ini untuk memberikan variasi data dan melihat perbandingan dari hasil pengumpulan data. Dalam penentuan informan, peneliti pada mulanya menelusuri infroamn melalui akun instagram@satuunaair dan@unairhitspeople, kemudian mencari informan yanga memiliki followers terbanyak dan yang sesuai dengan kriteria informan yang telah di jelaskan di atas.

Teknik pengumpulan data yang diperlukan dalam penelitian ini adalah observasi dan wawancara mendalam dengan menggunakan pedoman wawancara. Analisis data dalam penelitian kualitatif dilakukan pada saat pengumpulan data berlangsung dan setelah selesai pengumpulan data. Kemudian tahap-tahap analisis data menurut Sugiono diantaranya pengumpulan data, reduksi data, kategorisasi data, penyajian data, serta penarikan kesimpulan dan verifikasi data

\section{Hasil dan Pembahasan}

\section{Bagaimana Mahasiswa Universitas Airlangga Membentuk Citra Diri di Media Sosial Instagram}

Teknologi kini semakin canggih, mulai dari lahirnya smartphonne dan alat elektronik lainnya. salah satu teknologi yang saat ini banyak digunakan oleh masyarakat modern ini adalah internet. Internet salah satu teknologi yang dapat memberikan kemudahan bagi sang pengguna, pengguna insternet juga bukan hanya orang dewasa saja, namun saat ini dari orang dewasa hingga anak-anak sudah dapat mengguanakan internet.

Setelah lahirnya internet, kemudian muncullah beberapa media sosial yang lahir di sekitar pengguna internet. Para pengguna internet dimanjakan oleh beberapa fitur-fitur dan media sosial yang dapat menghibur para penggunanya. Lalu muncullah media sosial yang bernama instagram, instagram adalah media sosial yang gunanya selain untuk dapat menambah wawasan dan menambah teman, instagram juga dapat membagikan foto dan video sang pengguna. Di instagram juga di sediakan beberapa fitur yang dapat digunakan oleh pemilik akun ketika akan membagikan foto mereka di instagram.

Namun pemanfaat instagram saat ini bukan lagi menjadi media sosial untuk membagikan foto atau video saja, melainkan menjadi salah satu wadah untuk membentuk 
citra diri seorang pengguna atau sang pemilik akun instagram itu sendiri. Dengan cara dan trik tersendiri pengguna instagram dapat membentuk citra dirinya di instagram. Tujuan untuk membentuk citra diri itupun juga beragam.

Dalam fenomena tersebut, mahasiswa Universitas Airlangga menjadi salah satu mahasiswa yang membentuk citra diri di instagram. Universitas Airlangga adalah salah satu Universitas yang terkenal di Jawa Timur yang terletak di Surabaya. Beberapa mahasiswa dan mahasiswi Universitas Airlangga juga dapat dibilang hits atau terkenal dikalangan mahasiswa Universitas lain.

Mahasiswa Universitas Airlangga dalam membentuk citra diri di media sosial instagram emang berfariasi, namun salah satu atau beberapa mahasiswa membentuk citra diri mereka dengan beberapa hal yang sedikit hampir sama. Salah satu mahasiswa Universitas Airlangga membentuk citra dirinya dengan cara membagikan foto atau video yang menurutnya didalam foto tersebut mengandung makna atau sebuah informasi atau bahkan sebuah ajakan untuk mengajak para followers di instagramnya untuk berbuat positif.

Selain itu juga beberapa mahasiswa mengatakan bahwa membentuk citra diri mereka di instagram dengan cara membagikan foto-foto tentang passion-nya, seperti salah satu mahasiswa Universitas Airlangga yang membagikan fotonya di instagram ketika ia sedang membawakan acara di beberapa acara, kemudian membagikan foto ketika dia sedang bermain basket dan lain-lain. Hal tersebut menurutnya dapat membentuk citra diri mereka dengan tujuan akan semakin banyaknya tawaran pekerjaan untuknya.

Namun memang tidak selamanya citra diri di media sosial instagram membuahkan hal yang negatif, melainkan dari beberapa pernyataan mahasiswa Universitas Airlangga ini membuktikan bahwa membentuk citra diri di media sosial instagram ini juga membuahkan hasil yang positif, seperti semakin banyaknya yang mengenal sang pengguana melalui instagram, semakin banyaknya tawaran pekerjaan, bahkan followers instagram juga sangat berguna dan berpengaruh bagi seorang pengguna instagram untuk dalam hal pekerjaan.

Karena manurut beberapa pengguana instagram, semakin banyak followers atau pengikut di instagam, berarti akun instagram itu bukanlah akun yang biasa-biasa saja, melainkan pemilik akun instagram adalah seseorang yang memiliki kualitas, entah itu dari visual ataupun non visual. 
Dari keseluruhan mahasiswa Universitas Airlangga, ketika hendak akan membagikan foto atau video mereka di akun instagramnya, memberi editan adalah suatu hal yang wajib hukumnya bagi mereka. Bukan hanya itu saja, mahasiswa UNAIR juga memberikan polesan make up pada wajah mereka jika hendak mau berfoto yang nantinya akan di bagikan di instagram. selain wajah yang di perhatikan, ternyata penampilan juga sangatlah penting, dari salah satu mahasiswa laki-laki menyatakan bahwa penampilan dalam sebuah foto adalah hal yang penting, karena seseorang melihat pertama kali adalah penampilan.

Dengan memberikan polesan make up dan penampilan yang menarik, dapat menjadi salah satu cara mahasiswa membentuk citra diri mereka di instagram. Beberapa mahasiswa juga menyatakan bahwa tanpa make up di wajahnya ketika hendak akan berfoto, dia akan merasa tidak percaya diri. Namun dalam sehari-hari mahasiswa mengaku bahwa tidak mengenakan make up dan berpenampilan apa adanya, ber-make up dan berpenampilan menarik hanyalah untuk ketika akan mengambil sebuah foto saja.

\section{Alasan Mahasiswa Universitas Airlangga Membentuk Citra Diri di Media Sosial Instagram}

Dari beberapa mahasiswa Universitas Airlangga yang membentuk citra diri di instagram, mereka memiliki beberapa alasan mengapa membentuk citra diri di media sosial instagram. salah satu alasan mahasiswa membentuk citra diri di media sosial instagram yaitu agar lebih di kenal oleh orang lain, lebih banyak teman, semakin banyak tawaran pekerjaan bagi mereka.

Salah satu alasan mahasiswa membentuk citra diri di media sosial instagram yaitu karena, saat ini di jaman yang semakin modern ini, banyak perusahaan-perusahaan yang mencari dan me-rekrut calon karyawannya melalui media sosial atau memantaunya dari media sosial yang salah satunya yaitu instagram. bahkan perusahaanpun rela menyewa seseorang untuk me-stalking calon karyawannya itu. Maka dari itu salah satu dari mahasiswaUNAIR membentuk citra diri di instagram bukan lagi hanya sebagai kesenangan saja, melainkan juga untuk masa depan yang lebih baik lagi.

Beberapa alasan dari mahasiswa UNAIR membentuk citra diri di media sosial instagram ternyata tidak semua negatif atau hanya dijadikan senang-senang semata, melainkan juga untuk hal-hal kedepannya nanti. Dampak dari membentuk citra diri juga tidak selamanya menjadi hal yang negatif seperti yang ada di pikiran publik, melainkan dari citra diri yang di bentuk oleh seseorang di media sosial instagram juga dapat memberikan 
dampak positif bagi sang pengguna. Dengan semakin bertambahya fitur-fitur yang ada di instagram, kini instagram menjadi lebih asyik lagi dengan beberapa tambahan fitur seperti insta story, yang dimana pengguna instagram dapat membagikan storynya yang dapat dilihat selama 24 jam yang berdurasi sekitar 14 menit, hal tersebut, hal tersebut dapat memicu mahasiswa untuk semakin sering membuka instagram. Beberapa mahasiswa juga mengaku intensitas mereka dalam bermain internet atau instagram dalam sehari sangatlah sering, hampir setiap saat ketika ada waktu luang mereka akan membuka instagram.

\section{Pembahasan}

Disini peneliti akan kembali mencoba untuk mereview antara citra diri yang di bentuk oleh mahasiswa UNAIR di media sosial instagram dengan hiperrealitas serta intensitas mahasiswa dalam bermain internet yang juga termasuk bermain instagram dengan net generation.

Pada konsep hiperrealitas, yang arti dari hiperrealitas sendiri yaitu realitas yang di buat-buat dengan bantuan teknologi atau sentuhan editing dalam sebuah objek gambar yang dapat menjadikan suatu gambar menjadi lebih menarik, bukanhanya itu saja, namun juga citra diri yang di buat-buat yang dapat menjadi hiperrealitas atau yang di sebut sebagai realitas yang dibuat-buat. Kini mahasiswa menggunakan media sosial instagram bukan lagi untuk sekedar membagikan foto atau video saja, melainkan sebagai wadah untuk membentuk citra diri di media sosial instagram, dengan cara memberikan editan dalam setiap foto atau video yang akan di bagikan di instagram, kemudian menggunakan make up yang padahal dalam sehari-harinya tidak menggunakan make up, selain itu penampilan dalam foto juga menjadi point plus dalam sebuah foto yang akan di bagikan di instagram.

Dengan hal tersebut hiperrealitas terjadi karena adanya realitas yang dilebihlebihkan oleh pengguna instagram. selain memberikan make up atau berpenampilan menarik, mahasiswa juga membagikan foto-foto atau video yang menunjukkan passion mereka dengan tujuan agar orang yang melihat atau followers nya mengetahui bakat dan passion si pemilik akun tersebut. Hal tersebut bertujuan untuk membentuk citra diri mereka di depan publik.

Intensitas mahasiswa dalam bermain insternet yang juga termasuk instagram menjadi semakin tinggi, karena semakin berfariasi pula fitur-fitur yang ada di instagram, yang membuat pengguna instagram semakin tertarik bermain instagram setiap hari, setiap saat dan setiap waktu. Hal ini menjadi suatu budaya baru yaitu budaya internet. Seperti halnya net generation atau generasi internet, yang dimana 
anak muda saat ini lahir di kelilingi oleh teknologi-teknologi dan di besarkan dengan teknologi disekitarnya. Jadi anak muda jaman sekarang ini semakin ahli dalam mengoprassikan internet dalam kehidupan sehari-hari. Mulai dari mengerjakan tugas, mencari resep masakan, mencari tutorial hal-hal baru hingga bermain game. Internet memang menajadi hal yang membuat para penggunanya semakin terbantu dan memudahkan pengguna untuk melakukan hal-hal lainnnya. Kebiasaan ini disebut sebagai net generation atau generasi internet.

\section{Kesimpulan}

Dengan adanya internet, yang disusul munculnya beberapa media sosial yang kini banyak di gunakan oleh pengguna internt lainnya. Yaitu instagram, instagram kini menjadi media sosial yang banyak di gandrungi oleh pengguna internet lainnya. Selain dapat membagikan foto dan video, instagram juga menyajikan wadah untuk membentu citra diri di media sosial instagram.

Mahasiswa dan mahasiswi Universitas Airlangga sebelum membagikan sebuah foto atau video, selalu menyematkan editan dalam foto atau video tersebut. Kemudian mahasiswa dan mahasiswi Universitas Airlangga juga mengaku bahwa mereka membentuk citra diri di media sosial instagram dengan tujuan yang salah satu alasan mereka untuk membentuk citra diri yakni karena ingin di akui oleh publik tentang keberadaannya di dunia maya, kemudian ada juga yang menyatakan bahwa ingin memberikan dampak yang positif untuk lingkungan sekitar serta keingin untuk tawaran pekerjaan yang lebih banyak lagi.

Mahasiswa dan mahasiswi juga memberikan polesan makeup atau berdandan sebelum mengabadikan sebuah foto yang nantinya akan di bagikan di instagram. salah satu mahasiswa menyatakan merasa tidak percaya diri apabila membagikan foto atau video yang tanpa polesan di wajah. Selain itu salah satu mahasiswa lainnya juga menyatakan bahwa penampilan juga menunjang keindahan suatu objek dalam foto. Bukan hanya pakaian dan polesan wajah, namun juga gaya atau pose dalam sebuah foto juga menjadi nilai plus untuk membentuk citra diri diinstagram.

Selain dapat membentuk citra diri di media sosial instagram, tidak sepenuhnya berdampak negatif atau mendapat respon negatif dari orang sekitar, melainkan dari pernyataan yang telah di paparkan oleh informan yakni, dari citra diri yang telah di bentuknya, informan mendapatkan dampak positif.

Intensitas penggunaan media sosial instagram di kalangan mahasiswa dan mahasiswi Universitas Airlangga juga terbilang sangat sering. Dengan semakin 
berkembangnya teknologi akan semakin sering juga intensitas seserang dalam menggunakan teknologi yang berupa media sosial instagram.

\section{Referensi}

\section{Sumber Buku :}

Moleong, Lexy J. 1998. Metodologi Penelitian Kualitatif. Bandung: Remaja Rosdakarya.

Ritzer, George. 2014. Teori Sosiologi Modern. Jakarta : Kenccana.

Sugihartati, Rahma. 2014. Perkembangan Masyarakat Informasi dan Teori Sosial Kontemporer. Jakarta : Kencana Prenada Media Group.

Suyanto, Bagong. 2013. Sosiologi Ekonomi Kapitalisme Dan Konsumsi Di Era Masyarakat Post-Modernisme.Jakata : Kencana Prenada Media Group.

\section{Sumber E-Journal :}

Arya, Shandra. 2016, "Media Sosial Instagram Sebagai Aktualisasi Diri Bagi Komunitas Instagram Surabaya". Sosiologi Universitas Airlangga Surabaya.

Arlian, Putri Dwi. 2015. "Analisis Perilaku Pencarian Informasi Mengenai Breastfeeding Pada Ibu Net Generation”. Megister Media Dan Komunikasi Universitas Airlangga.

Ayun, Primada Qurrota. 2015. "Fenomena Remaja Menggunakn Media Sosial dalam Membentuk Identitas": Ilmu Komunikasi Universitas Ahmad Dahlan Yogyakarta.

Febriana, Merri. 2016, "Hiperrealitas Angka Dalam Instagram (Studi Fenomenologi Tentang Dampak Media Sosial Dikalangan Peserta Didik SMA Negri 14 Surakarta)"

Fitria, Herlinda. 2013, "Hiperrealitas Dalam Social Media (Studi Kasus: Makan Cantik Di Senopati Pada Masyarakat Perkotaan)".

Hardini, Amalia Puspita. 2010. "Hubungan Citra Diri Melalui Foto Profil Dengan Harga Diri Pada Mahasiswa Pengguna Facebook Fakultas Psikologi UIN Syarif Hidayatullah Jakarta": Fakultas Psikologi Universitas Islam Negri Syarif Hidayatullah Jakarta

Monica, Elsa. 2015. "Perilaku Konsumtif Mahasiswa Di Perkotaan Dalam Penggunaan Produk Perawatan Wajah Di Klinik Kecantikan”. Sosiologi Universitas Airlangga.

Khairunnisa, 2014, "Dampak Aplikasi Instagram Terhadap Perilaku Konsumtif Remaja Dalam Berbelanja Online Di Kalangan Siswa-Siswi SMA Negri 2 Tenggarong, Samarinda: Universitas Mulawarman. Junal Tidak Diterbitkan.”

Peristiwati, Maria. 2015, "Hiperrealitas Online Shop Dan Tindakan Konsumtif Melalui Jejaring Sosial Online"

Reshtyanti, Hilda. 2016, "Pencitraan Diri Dalam Media Sosial Path (Studi Deskriptif pada Pelajar SMA Negri 2 Surabya)".

Riyanti, Astri. 2010. "Fenomena Penggunaan Situs Jejaring Sosial Facebook Sebagai Ajang Penampilan Diri. Ilmu Komunikasi".

Setiyawan, Lathif Sihda. 2008. "Citra Diri Dalam Facebook". Sosiologi Universitas Airlangga.

\section{Sumber Internet:}


https://id.wikipedia.org/wiki/instagram di akses pada tanggal 18 Oktober 2017 pukul 22.51.

http://indahnyakomunikasi.wordpress.com/komunikasi/filsafat-ilmu-komunikasi/jean

baudrillard-hiperrealitas-dan-simulacra/ di akses pada tanggal 20 Oktober 2017 pukul 10:40

http://id.m.wikipedia.org/wiki/Media_sosial di akses pada tanggal 14 November 2017 pukul 20 